\title{
Effect of Wheat Straw Biochar on Thermophysical Properties of Loessial Soil
}

\author{
B. W. Zhao †, Y. Zhao, H. Liu, Y. Q. Li, K. X. Duan and X. Zhang
}

School of Environmental and Municipal Engineering, Lanzhou Jiaotong University, No. 88, West Anning Rd., Lanzhou 730070, P. R. China

$†$ Corresponding author: B. W Zhao; zhbw2001@ sina.com

Nat. Env. \& Poll. Tech. Website: www.neptjournal.com

Received: $22-08-2020$

Revised: $23-10-2020$

Accepted: 01-11-2020

Key Words:

Biochar

Bulk density

Thermophysical properties

Loessial soil

\begin{abstract}
Soil thermophysical properties are the key factors affecting the internal heat balance of soil. In this paper, biochars (BC300, BC500 and $\mathrm{BC} 700)$ were produced with wheat straw at the temperatures of 300,500 and $700^{\circ}$, respectively. The effects of biochar amendment at the rates of $0 \%, 1 \%, 3 \%$, and $5 \%$ on the thermophysical properties (thermal conductivity, heat capacity, and thermal diffusivity) of a loessial soil were investigated with and without water content respectively. Although the bulk density of soil significantly decreased with biochar amendment, due to enhancing soil porosity and organic matter content, the thermophysical properties of soil did not change largely with biochar amendment rate and pyrolysis temperature. Water content exhibited significant effects on the thermophysical properties of soils added with biochars, where the thermal conductivity and heat capacity of soil were linearly proportional to water content, the thermal diffusivity initially increased and then decreased with the increase of water content. In the meanwhile, there was no significant correlation between the biochar amendment rate or pyrolysis temperature and thermophysical properties. The results show that water content should be mainly concerned as a factor when the internal heat balance of loess soil is evaluated, even though the soil is amended with biochar.
\end{abstract}

\section{INTRODUCTION}

Biochar is a solid carbon material obtained by the pyrolysis of biomass (such as straw, sawdust, sludge, etc.) under high temperature and a limitative oxygen condition (Ding et al. 2016, Tripathi et al. 2016, Li et al. 2017). Related studies had shown that biochar played an important role in reducing greenhouse gas emission, slowing global warming, improving soil quality, promoting crop yields, and remedying contaminated soil (Chan et al. 2007, Liu et al. 2012, Herath et al. 2013, Lu et al. 2014, Lehmann \& Joseph 2015, Elzobair et al. 2016, Lin et al. 2019). As a large agricultural country, China has abundant straw resources, and the current disposal of straw in China has always been an environmental problem. According to statistics, the annual amount of straw by incineration in China is about $1.4 \times 10^{8} \mathrm{t}$ (Mohan et al. 2014), which causes severe pollution to the atmospheric environment. To realize the proper disposal and utilization of straw, it is an economical and feasible way to convert straw into biochar. In addition, loess soil is widespread and accounts for one-tenth of the global land area. Loess soil has the characteristics of loose structure, large porosity and water permeability, low agglomerating force, and organic matter content, which result in nutrient leaching from the loess soil, causing the soil to have poor quality (Tuo et al. 2017). Therefore, biochar could be a modifier to improve the fertility of loess soil and enhance crop yields.
Biochar amendment into the soil will change the composition and properties of soil, such as soil organic matter and bulk density, and thus indirectly affect the soil thermophysical properties and temperature (Wang et al. 2009). Zhang et al. (2013) found that the application of biochar could reduce daily or seasonal temperature fluctuations of soil. Genesio et al. (2012) found that the soil treated by biochar had an albedo being lower than that of the control by $80 \%$. During the crop growing season, the albedo of soil treated by biochar decreased by $20-26 \%$. Usowicz et al. (2016) noted that there was no significant change in soil thermal conductivity and thermal diffusivity after application of biochar in grassland, while in fallow land, both of them decreased with the increase of biochar amendment. Yadav \& Saxena (1973) found that the heat capacities of sand and clay were a linear function of the water content, and the compaction treatment had no significant effect on the heat capacity of the soil. However, there have been few studies on the effect of biochar amendment on the thermophysical properties of loess soil.

Thus, the loessial soil was sampled, wheat straw was used as the biomass to prepare biochar, and the biochar was added into the loessial soil. The changing laws and mechanisms of wheat straw biochar influencing the thermophysical properties of loessial soil were explored. The results could provide a reference for the subsequent evaluation of the physical environmental effects of biochar on loess soil. 


\section{MATERIALS AND METHODS}

\section{Biochars and Soil}

Wheat straw was obtained in Wushan County, Tianshui City, Gansu Province, China. The straw was washed 3 times with tap water, air-dried for 2 days, and dried in an oven at $70-80^{\circ} \mathrm{C}$ overnight. Then the straw was crushed and passed through a 40 mesh sieve. The straw crumbs were put into a crucible with compaction and pyrolyzed in a muffle furnace (HWL$12 \mathrm{XC}$, Shandong Huawei Luye company, China) at 300, 500 and $700^{\circ} \mathrm{C}$ for $6 \mathrm{~h}$, and then taken out after the sample was cooled (Ren et al. 2018). The biochars were denoted as $\mathrm{BC} 300, \mathrm{BC} 500$ and BC700. The basic properties of biochars are listed in Table 1, where the yield of the biochar was obtained by the ratio of the sample mass difference before and after pyrolysis to the mass of biomass; the $\mathrm{pH}$ value was measured by the potentiometric method (Zhou et al. 2015); the content of $\mathrm{C}, \mathrm{H}$, and $\mathrm{N}$ in biochar was determined by an element analyzer (Vario EL, Elementar, Germany), and the content of $\mathrm{O}$ was calculated by a subtraction method (Peterson et al. 2012); the average pore size and the specific surface area were measured by BET physical adsorption instrument (Autosorb-1, Quantachrome, USA).

The loessial soil was sampled from the $0-20 \mathrm{~cm}$ surface soil at Elephant Mountain Town, Gangu County, Tianshui City, Gansu Province, China, which is the cultivated soil for growing wheat all year round. The impurities such as small stones, rhizomes, and leaves were removed. The soil sample was air-dried and passed through a 40 mesh sieve for use. The basic properties of soil are also listed in Table 1, where the total carbon was determined by soil carbon and nitrogen analyzer (DK-3, Shenzhen Deka Precision Instrument Company, China); the moisture content was determined by calculating the ratio of the difference between the quantity of the sample before and after drying to the initial quantity of the sample; the organic matter content was obtained by potassium dichromate oxidation method (Shuang et al. 2016); the porosity was measured by the standard method (GB/T 24203-2009); for determining bulk density, a sample of $100 \mathrm{~mL}$ was taken, its mass weighted, and the ratio of mass to volume calculated.

\section{Experimental Design}

The biochars were thoroughly mixed with loessial soil in the amount of $0 \%, 1 \%, 3 \%$, and 5\% (mass ratio) and placed in a $100 \mathrm{~mL}$ plastic container with a sealed lid. The containers were put into an incubator at $25^{\circ} \mathrm{C}$ for one week to ensure the equilibrium and then the bulk density, organic matter content, and thermophysical properties of soils were determined. Three parallel samples were set for each run. The sample with no biochar addition was the control (CK). The treatments with $\mathrm{BC} 300, \mathrm{BC} 500$ and $\mathrm{BC} 700$ at the amendment rates of $1 \%$, $3 \%$ and $5 \%$ were denoted as $\mathrm{BC} 300-1, \mathrm{BC} 300-3, \mathrm{BC} 300-$ 5; BC500-1, BC500-3, BC500-5; BC700-1, BC700-3 and BC700-5, respectively. As far as the effects of water content on the thermophysical properties were concerned, distilled water was added at the rates of $0 \%, 20 \%, 30 \%$, and $40 \%$ respectively into the soil sample under different treatments.

\section{Determination Methods}

The determinations of organic matter content and bulk density of loessial soil were the same as mentioned in the earlier section. The thermophysical properties of loessial soil were analyzed by KD2 Pro thermal characteristic analyzer (METER Group, Inc., USA).

\section{Data Analysis}

Origin Pro 8.5 software was used for data fitting; SPSS 19.0 statistical analysis software was used for Pearson correlation analysis and the least significant difference method was used for multiple comparisons (Uppercase letters represented differences between groups, lowercase letters represented differences within groups).

\section{RESULTS AND DISCUSSION}

\section{Effect of Biochar on Soil Property without Water Content}

The effects of biochars on the bulk density of loessial soil are shown in Fig. 1. Biochar amendment had significant effects on the bulk density of loessial soil. The bulk density of CK was $1.002 \mathrm{~g} . \mathrm{cm}^{-3}$, and the decreasing percentages of bulk

Table 1: Basic properties of biochars and soil.

\begin{tabular}{|c|c|c|c|c|c|c|c|c|}
\hline \multirow[t]{2}{*}{ Biochar } & \multirow[t]{2}{*}{ Yield (\%) } & \multirow[t]{2}{*}{$\mathrm{pH}$} & \multirow{2}{*}{$\begin{array}{l}\text { Average pore } \\
\text { size }(\mathrm{nm})\end{array}$} & \multirow{2}{*}{$\begin{array}{l}\text { Specific surface } \\
\text { area }\left(\mathrm{m}^{2} \cdot \mathrm{g}^{-1}\right)\end{array}$} & \multicolumn{4}{|c|}{ Element $(\%)$} \\
\hline & & & & & $\mathrm{C}$ & $\mathrm{H}$ & $\mathrm{O}$ & $\mathrm{N}$ \\
\hline ВС 300 & 45.63 & 7.11 & l & 0.43 & 63.10 & 3.91 & 27.07 & 0.46 \\
\hline BC500 & 27.22 & 9.66 & 2.33 & 23.12 & 71.41 & 2.83 & 19.72 & 0.58 \\
\hline BC700 & 23.94 & 10.43 & 2.00 & 311.51 & 86.60 & 1.86 & 5.47 & 0.61 \\
\hline Soil & & Total carbon $(\%)$ & $\mathrm{pH}$ & Organic matter $(\%)$ & & Porosity $(\%)$ & Bulk & $\left(\mathrm{g} / \mathrm{cm}^{3}\right)$ \\
\hline Loessial soil & & 2.2 & 8.22 & 0.79 & & 60.9 & 1.002 & \\
\hline
\end{tabular}


density in soils with BC300-1, BC500-1, and BC700-1 were $12.9 \%, 6.4 \%$ and $4.4 \%$; BC300-3, BC500-3, and $\mathrm{BC} 700-3$ were $23.8 \%, 16.3 \%$ and $13.6 \%$; $\mathrm{BC} 300-5, \mathrm{BC} 500-5$, and BC700-5 were $36.4 \%, 24.9 \%$ and $21.7 \%$, respectively.

The reduction in bulk density of soil could be attributed to the increment in the organic matter content and porosity of soil due to biochar amendment. The effects of BC300, $\mathrm{BC} 500$, and $\mathrm{BC} 700$ on the organic matter content of loessial soil are shown in Fig. 2. It can be observed that the organic matter content of loessal soil significantly increased by BC300, BC500, and BC700 amendment The organic matter content of CK was $0.79 \%$, and the increasing percentages of organic matter in soils with BC300-1, BC500-1, and BC7001 were $55.7 \%, 67.1 \%$, and $75.9 \%$; $\mathrm{BC} 300-3, \mathrm{BC} 500-3$, and BC700-3 were $164.6 \%, 169.6 \%$, and $219.0 \%$; BC300-5, BC500-5, and BC700-5 were 226.6\%, 225.3\%, and 229.1\%, respectively. Hua et al. (2014) also found that the effect of biochar on soil with low organic matter content was significantly higher than that with high organic content. In addition, biochar has a low density and rich pore structure (Lehmann \& Joseph 2015). According to the relevant research, the soil bulk density was related to the soil porosity and compaction (Neves et al. 2003, Hong et al. 2011, Wu et al. 2015, Das et al. 2017, Zhao et al. 2018). Biochar amendment would result in increasing of soil porosity and decreasing soil bulk density. The conclusion was consistent with previous research results (Oguntunde et al. 2008).

The effects of biochar amendment on the thermophysical properties of loessial soil without water content are shown in Fig. 3. The thermal conductivity of soils with BC300-1, BC500-1 and BC700-1 were 0.193, 0.195 and $0.201 \mathrm{w} \cdot \mathrm{m} \cdot \mathrm{K}^{-1}$; BC300-3, BC500-3 and BC700-3 were 0.173, 0.180 and $0.188 \mathrm{w} \cdot \mathrm{m} \cdot \mathrm{K}^{-1}$; while $\mathrm{BC} 300-5, \mathrm{BC} 500-5$ and $\mathrm{BC} 700-5$

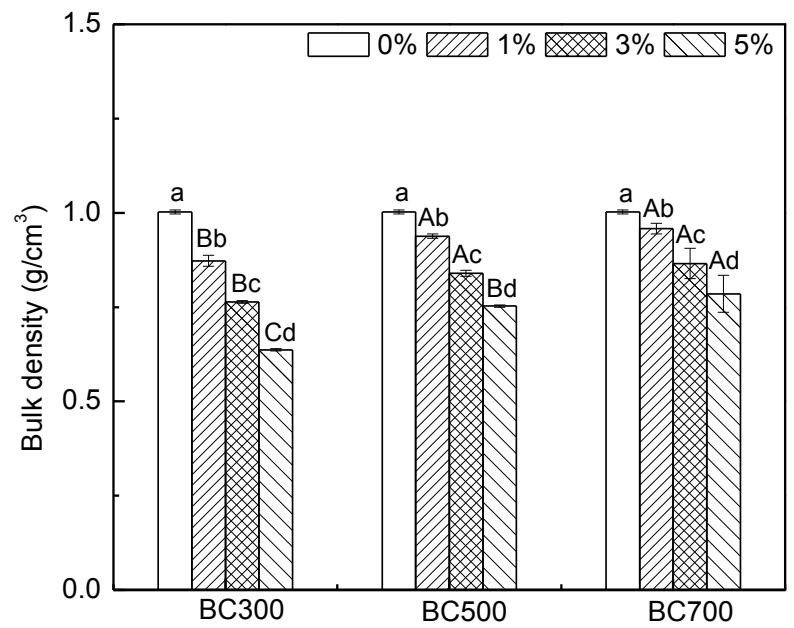

Fig. 1: Effects of biochars on bulk density of loessial soil were $0.167,0.173$ and $0.181 \mathrm{w} \cdot \mathrm{m} \cdot \mathrm{K}^{-1}$, respectively (Fig. 3a). The thermal conductivity of loessial soil increased by the biochar addition at the rate of $1 \%$. The thermal conductivity was inversely proportional to the biochar addition amount. The reason was that the thermal conductivity of biochar itself was low and the addition of biochar was conducive to the formation of large pores in loessial soil. In addition, the increase of organic matter content of loessial soil was also an important reason for the decrease of thermal conductivity with the increase of biochar addition amount (Abu-Hamdeh et al. 2000).

As seen from Fig. 3b, when compared with CK, the heat capacity of soils with BC700-1 and BC700-3 increased by $6.7 \%$ and $1.6 \%$, respectively. The heat capacity decreased by the addition of biochar at the rate of $5 \%$. Since the organic matter content of loessial soil increased by the high addition of biochar, the organic matter content was an important factor for the decline of the heat capacity (Abu-Hamdeh et al. 2000, Zhao et al. 2016). The heat capacity of loessial soils added with BC500 and BC700 reduced with the increase of biochar amendment, where those with BC500-1, BC500-3, and BC500-5 were $1.104,1.046$, and $1.035 \mathrm{MJ} \cdot \mathrm{m}^{3} \cdot \mathrm{K}^{-1}$, respectively. However, the changing laws between the heat capacity and the addition amount with BC300 were not significant.

Thermal diffusivity is the ratio of thermal conductivity to thermal capacity. The effects of biochars on the thermal diffusivity of loessial soil are shown in Fig. 3c. When compared with the CK, the thermal diffusivity of soils with BC300-1, BC500-1, BC700-1, and BC700-5 increased by $0.99 \%, 3.0 \%$, $1.2 \%$, and $3.0 \%$, respectively. The thermal diffusivity of loessial soils with BC300-3, BC500-3, BC500-5, and BC700-3 decreased by $4.9 \%, 8.5 \%, 1.2 \%$, and $0.79 \%$, respectively. The addition of BC300 and BC500 was inversely proportional to

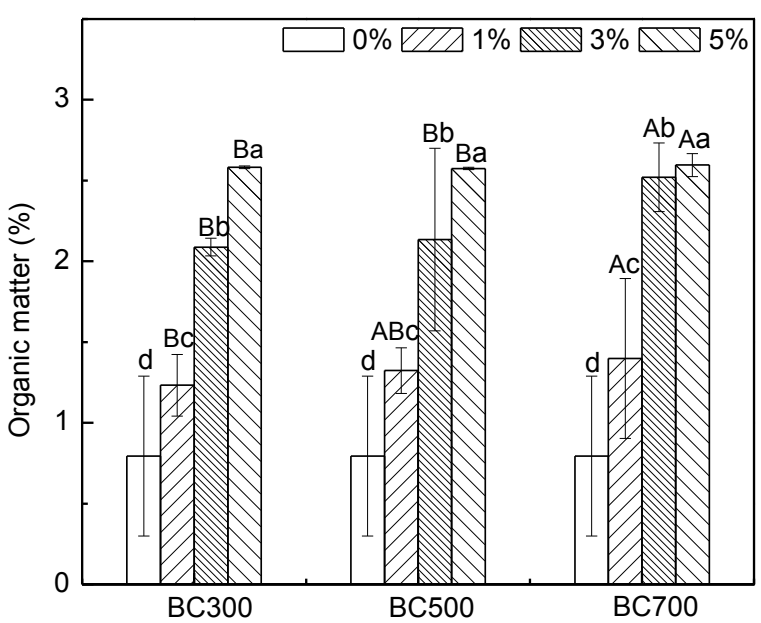

Fig. 2: Effects of biochars on organic matter contents of the soil. 


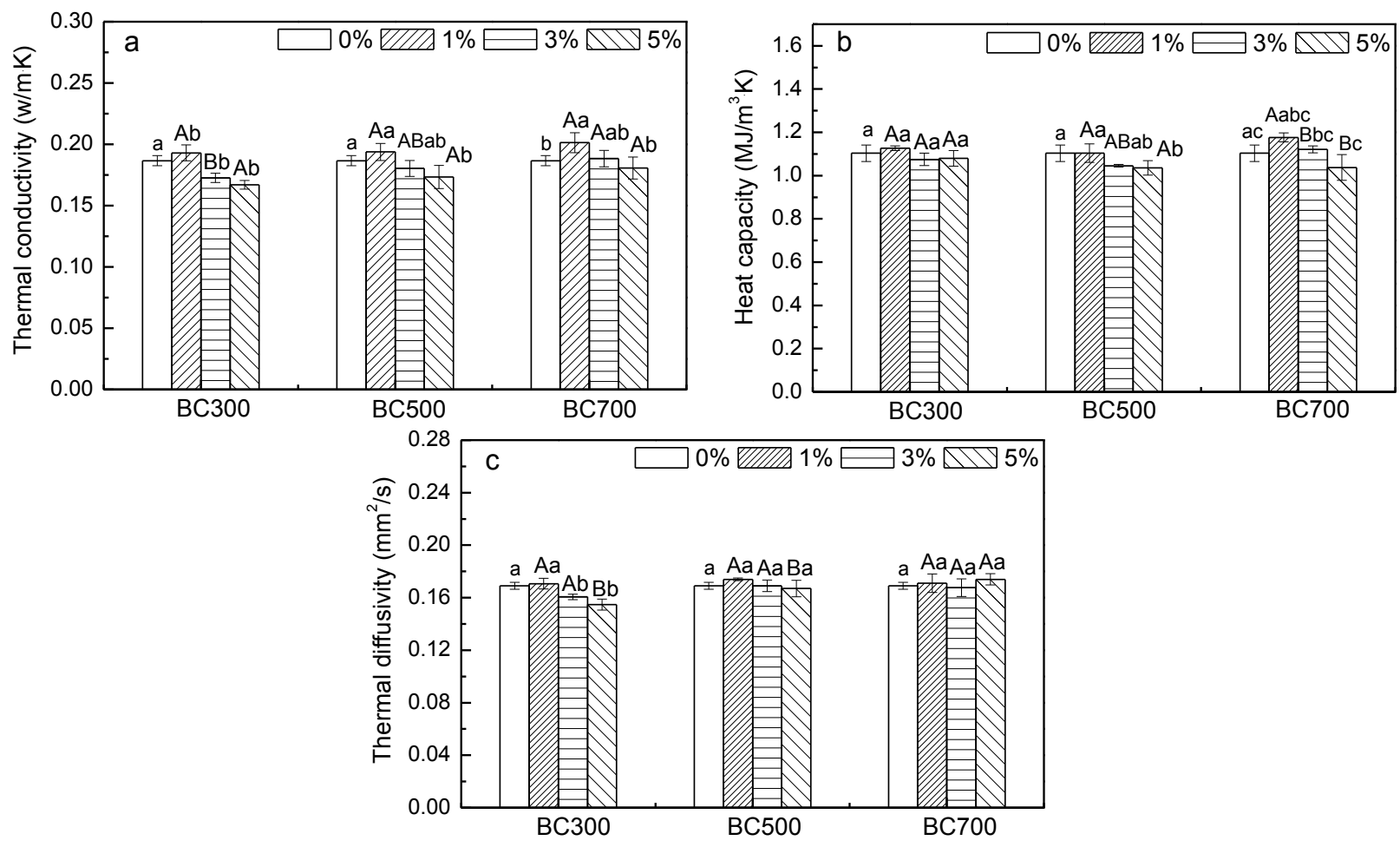

Fig. 3: Effects of biochars on thermal conductivity (a), heat capacity (b) and thermal diffusivity (c) of loessial soil.

the thermal diffusivity. It was mainly due to the low thermal diffusivity of the biochar itself (Bachmann et al. 2001, Zhao et al. 2016). The effect of pyrolysis temperature on the heat capacity and the thermal diffusivity of loessial soil was not significant (Usowicz et al. 2014).

\section{Effect of Biochar on Soil Property with Water Content}

The effects of water content on the thermophysical properties of loessial soil are illustrated using BC300 systems and shown in Fig. 4 (no data shown for BC500 and BC700 systems). There was a close linear positive correlation between the thermal conductivity and water content with biochar amendment, indicating that the thermal conductivity could be heavily affected by a slight change in water content. The reason is that the thermal conductivity of water is almost 30 times that of air and the thermal conductivity was increased by the formed water film (Zhao et al. 2016). When the water content was $0 \%$ and $40 \%$, the thermal conductivity of soils with BC300-5 was 0.2 and $1.19 \mathrm{w} \cdot \mathrm{m} \cdot \mathrm{K}^{-1}$, respectively, with an increase of $495 \%$, which shows that the thermal conductivity would be greatly improved by water content.

The effects of water content on the heat capacity of loessial soil are shown in Fig. 4b. There was a close linear positive correlation between heat capacity and water content. When the water content was $0 \%$ and $40 \%$, the heat capacity of soils with $\mathrm{BC} 300-5$ was 0.87 and $2.50 \mathrm{MJ} \cdot \mathrm{m}^{-3} \cdot \mathrm{K}^{-1}$, respectively, with an increase of $187 \%$. The reason is that the specific heat capacity of water is much larger than that of air and the positive effect of the heat capacity caused by increasing the water content was significantly higher than the negative effect caused by increasing porosity.

The effects of water content on the thermal diffusivity of loessial soil are shown in Fig. 4c. The fitted curves between the thermal diffusivity and water content are logarithmic. The thermal diffusivity of loessial soils with biochar amendment initially increased and then decreased with the increase of water content. The peak thermal diffusivity of soils with CK, BC300-1, BC300-3, and BC300-5 were 0.415, 0.433, 0.389 and $0.349 \mathrm{~mm}^{2} . \mathrm{s}^{-1}$, respectively. At low water content, the thermal conductivity of loessial soil increased with the water content more obviously than the heat capacity, and after the peak value, the heat capacity increased with the moisture content more obviously than the thermal conductivity, which caused the thermal diffusivity to increase and then decrease (Bachmann et al. 2001).

\section{Correlation Analysis}

The correlation between the thermophysical properties of 
loessial soil added with biochars and influencing factors is shown in Table 2. In the absence of water content, there was a significant correlation between the thermal properties and the biochar amendment rate and the bulk density of soil. There was a significant negative correlation between the biochar amendment rate and thermal conductivity, heat capacity, and thermal diffusivity with correlation coefficients of $-0.532 * *$, $-0.549^{* *}$, and $-0.411^{*}$, respectively. A significant positive correlation was found between the bulk density of soil and the thermophysical properties, with high correlation coefficients of $0.908^{* *}, 0.852^{* *}$ and $0.869^{* *}$. However, with water content, the thermal properties were only significantly correlated with the water content. The correlation coefficients of thermal conductivity, heat capacity, and thermal diffusivity were $0.936^{* *}, 0.957^{* *}$ and $0.841^{* *}$, respectively, which showed that water content was the main factor to evaluate the internal heat balance of loess soil, even though the loessial soil was treated with biochars.

\section{CONCLUSIONS}

Wheat straw biochar amendment could enhance the porosity
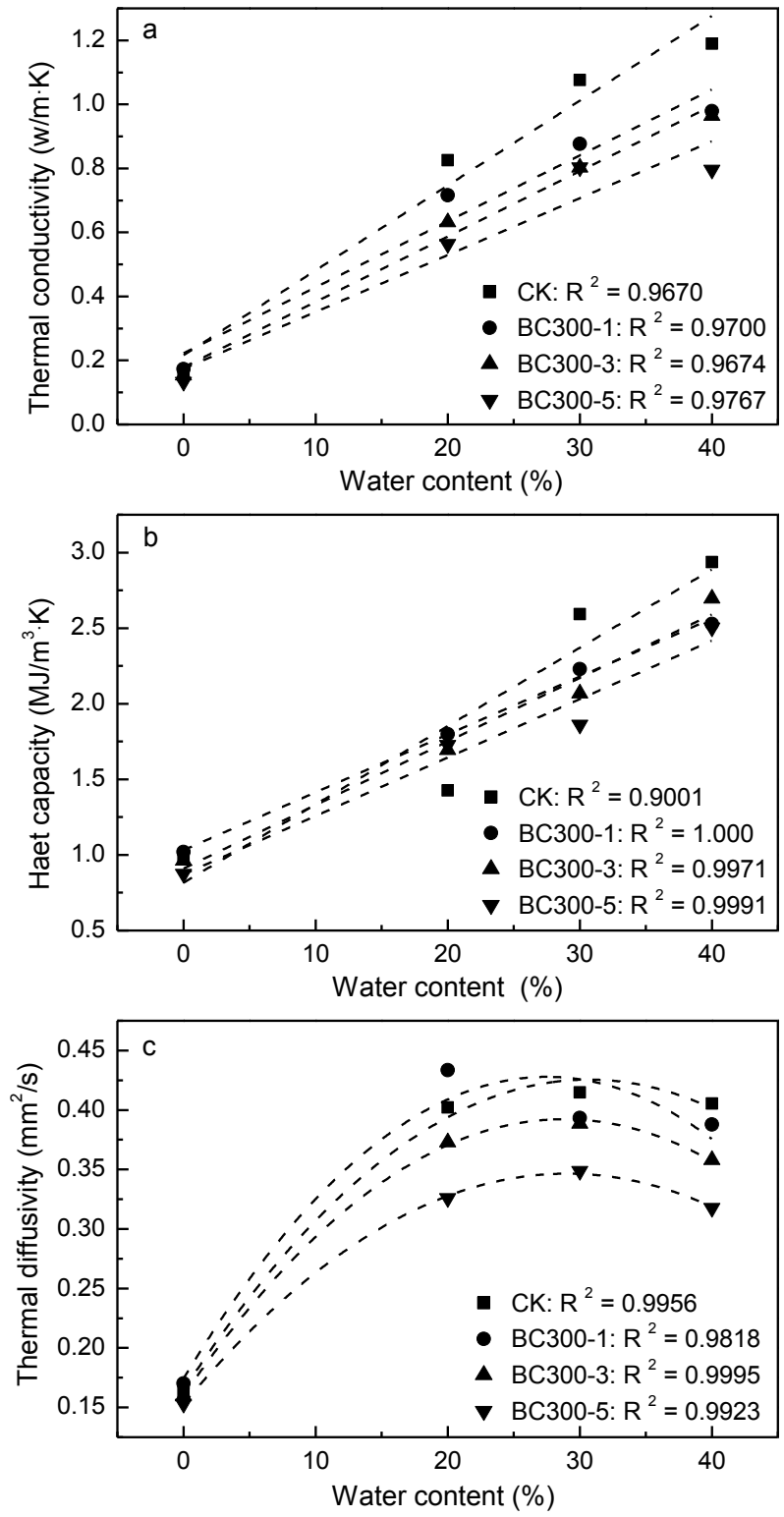

Fig. 4: Effects of water content on thermal conductivity (a), heat capacity (b) and thermal diffusivity (c) of loessial soil. 
Table 2: Correlation between thermophysical properties and influencing factors.

\begin{tabular}{|c|c|c|c|c|c|c|}
\hline & \multirow[t]{2}{*}{ Thermal property } & \multicolumn{5}{|c|}{ Factor } \\
\hline & & \multicolumn{2}{|c|}{ Pyrolysis temperature } & \multicolumn{2}{|c|}{ Biochar amendment rate } & Bulk density \\
\hline \multirow{5}{*}{$\begin{array}{l}\text { Without water } \\
\text { content }\end{array}$} & Thermal conductivity & 0.169 & & $-0.532 * *$ & & $8 * *$ \\
\hline & Heat capacity & 0.132 & & $-0.549 * *$ & & $52 * *$ \\
\hline & Thermal diffusivity & 0.221 & & $-0.411 *$ & & $69 * *$ \\
\hline & \multirow[t]{2}{*}{ Thermal property } & \multicolumn{5}{|c|}{ Factor } \\
\hline & & Water content & $\begin{array}{l}\mathrm{Bic} \\
\text { rat }\end{array}$ & endment & Pyrolysis & Bulk density \\
\hline \multirow{3}{*}{$\begin{array}{l}\text { With water } \\
\text { content }\end{array}$} & Thermal conductivity & $0.936^{* *}$ & -0 & & -0.012 & 0.18 \\
\hline & Heat capacity & $0.957 * *$ & -0 . & & 0.01 & 0.091 \\
\hline & Thermal diffusivity & $0.841 * *$ & -0 & & -0.012 & 0.176 \\
\hline
\end{tabular}

* Significant correlation at 0.05 level; ** Significant correlation at 0.01 level

and organic matter content of loessial soil. Thus, the bulk density of loessial soil decreased significantly with the biochar amendment rate. Without water content, although the thermal conductivity, heat capacity, and thermal diffusivity of soil did not change largely with biochar amendment rate and pyrolysis temperature, there was a significant negative correlation between the biochar amendment rate and thermal properties, while there was a significant positive correlation between the bulk density of soil and the thermophysical properties. In the presence of water content, there was no significant correlation between the biochar amendment rate and pyrolysis temperature and thermophysical properties. The thermophysical properties changed significantly with water content increasing. It is shown that water content was a more important factor to evaluate the internal heat balance of loess soil.

\section{ACKNOWLEDGMENT}

This work was financially supported by the National Natural Science Foundation of China $(51766008,21467013$, 21167007).

\section{REFERENCES}

Abu-Hamdeh, N. H. and Reeder, R. C. 2000. Soil thermal conductivity effects of density, moisture, salt concentration, and organic matter. Soil Sci. Soc. Am. J., 64: 1285-1290.

Bachmann, J., Horton, R., Ren, T. and Van der Ploeg, R. R. 2001. Comparison of the thermal properties of four wettable and four water-repellent soils. Soil Sci. Soc. Am. J., 65: 1675-1679.

Chan, K. Y., Van Zwieten, L., Meszaros, I., Downie, A. and Joseph, S. 2007. Agronomic values of greenwaste biochar as a soil amendment. Aust. J. Soil Res., 45: 629-634.

Das, O., Kim, N., Kalamkarov, A. L., Sarmah, A. K. and Bhattacharyya, D. 2017. Biochar to the rescue: Balancing the fire performance and mechanical properties of polypropylene composites. Polym. Degrad. Stabil., 144: 485-496.
Ding, Z., Wan, Y., Hu, X., Wang, S. and Zimmerman, A. R. 2016. Sorption of lead and methylene blue onto hickory biochars from different pyrolysis temperatures: importance of physicochemical properties. J. Ind. Eng. Chem., 37: 261-267.

Elzobair, K. A., Stromberger, M. E. and Ippolito, J. A. 2016. Stabilizing effect of biochar on soil extracellular enzymes after a denaturing stress. Chemosphere, 142: 114-119.

Genesio, L., Miglietta, F., Lugato, E., Baronti, S., Pieri, M. and Vaccari, F. P. 2012. Surface albedo following biochar application in durum wheat. Environ. Res. Lett., 7: 014025.

Herath, H. M. S. K., Camps-Arbestain, M. and Hedley, M. 2013. Effect of biochar on soil physical properties in two contrasting soils: An Alfisol and an Andisol. Geoderma, 209-210: 188-197.

Hong, X., Zhang, L., Wei, G. and Qing, Z. 2011. Effects of biochar amendment on cropland soil bulk density, cation exchange capacity, and particulate organic matter content in the North China Plain. J. Appl. Ecol., 22: 2930-2934.

Hua, L., Lu, Z., Ma, H. and Jin, S. 2014. Effect of biochar on carbon dioxide release, organic carbon accumulation, and aggregation of soil. Environ. Prog. Sustain. Energy, 33: 941-946.

Lehmann, J. and Joseph, S. 2015. Biochar for Environmental Management: Science, Technology and Implication. Routledge, New York. pp 33-46.

Li, B., Yang, L., Wang, C., Zhang, Q., Liu, Q. and Li, Y. 2017. Adsorption of $\mathrm{Cd}$ (II) from aqueous solutions by rape straw biochar derived from different modification processes. Chemosphere, 175: 332-340.

Lin, Y., Yi, S., Zhang, Z., Wang, M. and Nie, T. 2019. Study on the effect of water, fertilizer, and biochar interaction on $\mathrm{N}_{2} \mathrm{O}$ emission reduction in paddy fields of northeast China. Nat. Environ. Pollut. Technol., 18(3): 955-961.

Liu, X. H., Han, F. P. and Zhang, X. C. 2012. Effect of biochar on soil aggregates in the Loess Plateau: Results from incubation experiments. Int. J. Agr. Biol., 14: 975-979.

Lu, N., Liu, X. R., Du, Z. L., Wang, Y. D. and Zhang, Q. Z. 2014. Effect of biochar on soil respiration in the maize growing season after 5 years of consecutive application. Soil Res., 52: 505-512.

Mohan, D., Sarswat, A., Ok, Y. S. and Pittman, C. U. 2014. Organic and inorganic contaminants removal from water with biochar, a renewable, low cost and sustainable adsorbent: A critical review. Bioresource Technol., 160: 191-202.

Neves, C. S. V. J., Feller, C., Guimarães, M. F., Median, C. C. and Fortier, M. 2003. Soil bulk density and porosity of homogeneous morphological units identified by the cropping profile method in clayey Oxisols in Brazil. Soil Till. Res., 71: 109-119. 
Oguntunde, P. G., Abiodun, B. J., Ajayi, A. E. and Nick, V. D. G. 2008. Effects of charcoal production on soil physical properties in Ghana. J. Plant Nutr. Soil Sci., 171: 591-596.

Peterson, S. C., Appell, M. and Jackson, M. A. 2012. Comparing corn stover and switch grass biochar: Characterization and sorption properties. J. Agr. Sci., 5: 1-8.

Ren, X., Wang, F., Zhang, P., Guo, J. and Sun, H. 2018. Aging effect of minerals on biochar properties and sorption capacities for atrazine and phenanthrene. Chemosphere, 206: 51-58.

Shuang, L., Ni, S. N., Du, J., Ying, C. Y. and Shi, C. G. 2016. Determination of organic carbon content in geochemical exploration soil samples by potassium dichromate oxidation-external heating method. Anhui Chem. Ind., 42: 110-112.

Tripathi, M., Sahu, J. N. and Ganesan, P. 2016. Effect of process parameters on production of biochar from biomass waste through pyrolysis: A review. Renew. Sus. Energy. Rev., 55: 467-481.

Tuo, D., Xu, M., Li, Q. and Liu, S. 2017. Soil aggregate stability and associated structure affected by long-term fertilization for a loessial soil on the loess plateau of China. Polish J. Environ. Stud., 230: 849-861.

Usowicz, B., Lipiec, J., Łukowski, M., Marczewski, W. and Usowicz, J. 2016. The effect of biochar application on thermal properties and albedo of loess soil under grassland and fallow. Soil Till. Res., 164: 45-51.

Usowicz, B., Lukowski, M. and Lipiec J. 2014. Thermal properties of soils: Effect of biochar application. EGU General Assembly, 16: 9533.

Wang, Y., Chen, S., Sun, H. and Zhang, X. 2009. Effects of different cultivation practices on soil temperature and wheat spike differentiation. Cereal Res. Commun., 37: 575-584.

Wu, W., Sun, X., Dong, D. and Wang, H. N. 2015. Environmental Effects of Biochar in Soil. Science Press, Beijing.

Yadav, M. R. and Saxena, G. S. 1973. Effect of compaction and moisture content on specific heat and thermal capacity of soils. J. Ind. Soc. Soil Sci., 21: 129-132.

Zhang, Q., Wang, Y., Wu, Y., Wang, X., Du, Z. and Liu, X. 2013. Effects of biochar amendment on soil thermal conductivity, reflectance, and temperature. Soil Sci. Soc. Am. J., 77: 1478-1487.

Zhao, J., Ren, T., Zhang, Q., Zhang, Q. and Du, Z. 2016. Effects of biochar amendment on soil thermal properties in the North China Plain. Soil Sci. Soc. Am. J., 80: 1157-1166.

Zhao, S., Ta, N., Li, Z., Yang, Y., Zhang, X. and Liu, D. 2018. Varying pyrolysis temperature impacts application effects of biochar on soil labile organic carbon and humic fractions. Appl. Soil Ecol., 123: 484-493. 